\title{
Effects of Adolescent Caffeine Consumption on Cocaine Sensitivity
}

\author{
Casey E O’Neill', Sophia C Levis', Drew C Schreiner', Jose Amat', Steven F Maier' and Ryan K Bachtell*,1,2 \\ 'Department of Psychology and Neuroscience, Center for Neuroscience, University of Colorado, Boulder, CO, USA; 'Institute for Behavioral \\ Genetics, University of Colorado Boulder, Boulder, CO, USA
}

\begin{abstract}
Caffeine is the most commonly used psychoactive substance, and consumption by adolescents has risen markedly in recent years. We identified the effects of adolescent caffeine consumption on cocaine sensitivity and determined neurobiological changes within the nucleus accumbens (NAc) that may underlie caffeine-induced hypersensitivity to cocaine. Male Sprague-Dawley rats consumed caffeine $(0.3 \mathrm{~g} / \mathrm{l})$ or water for 28 days during adolescence (postnatal day 28-55; P28-P55) or adulthood (P67-P94). Testing occurred in the absence of caffeine during adulthood (P62-82 or PIOI-12I). Cocaine-induced and quinpirole $\left(\mathrm{D}_{2}\right.$ receptor agonist)-induced locomotion was enhanced in rats that consumed caffeine during adolescence. Adolescent consumption of caffeine also enhanced the development of a conditioned place preference at a sub-threshold dose of cocaine $(7.5 \mathrm{mg} / \mathrm{kg}$, i.p.). These behavioral changes were not observed in adults consuming caffeine for an equivalent period of time. Sucrose preferences were not altered in rats that consumed caffeine during adolescence, suggesting there are no differences in natural reward. Caffeine consumption during adolescence reduced basal dopamine levels and augmented dopamine release in the NAc in response to cocaine (5 mg/ $/ \mathrm{kg}$, i.p.). Caffeine consumption during adolescence also increased the expression of the dopamine $D_{2}$ receptor, dopamine transporter, and adenosine $A_{1}$ receptor and decreased adenosine $A_{2 A}$ receptor expression in the NAc. Consumption of caffeine during adulthood increased adenosine $A_{1}$ receptor expression in the NAc, but no other protein expression changes were observed. Together these findings suggest that caffeine consumption during adolescence produced changes in the NAc that are evident in adulthood and may contribute to increases in cocaine-mediated behaviors.
\end{abstract}

Neuropsychopharmacology (2015) 40, 8I3-82I; doi: I0.1038/npp.2014.278; published online 19 November 2014

\section{INTRODUCTION}

Caffeine is the most commonly used psychostimulant in the world (Rath, 2012). Caffeine is found naturally in coffee, tea and chocolate and is increasingly added as a supplement to other beverages including soda and energy drinks. Consumption of caffeine among adolescents has risen markedly in recent years in that daily caffeine consumption in 9- to 17-year olds has more than doubled since 1980 (Frary et al, 2005). Caffeine intake is positively correlated with substance-use disorders (Kendler et al, 2006), illicit drug use and other risky behaviors in young adults (Miller, 2008). Although moderate caffeine consumption in adults is considered relatively safe, there has been little research examining the long-term consequences of caffeine on the behavioral and neurobiological systems associated with substance use (Temple, 2009).

The psychostimulant actions of caffeine primarily result from nonselective blockade of both adenosine $A_{1}$ and $A_{2 A}$

\footnotetext{
*Correspondence: Dr RK Bachtell, Department of Psychology and Neuroscience, University of Colorado, Campus Box 345, UCB 345, Boulder, CO 80309-0345, USA, Tel: + 303735 1012, Fax: + 303 492 2967, E-mail: Ryan.Bachtell@Colorado.edu

Received 28 July 2014; revised 25 September 2014; accepted 6 October 2014; accepted article preview online 20 October 2014
}

receptors throughout the brain (Fredholm et al, 1999). Adenosine $A_{1}$ and $A_{2 A}$ receptors are localized in the brain with very dense expression in striatal areas such as the nucleus accumbens (NAc) and caudate-putamen. Blockade of adenosine receptors within the striatal regions amplifies dopamine neurotransmission (Fuxe et al, 2007). Caffeine increases extracellular dopamine in the striatum and prefrontal cortex (Borycz et al, 2007; De Luca et al, 2007; Solinas et al, 2002) and dopamine receptor antagonism blocks caffeine-induced locomotor activity (Garrett and Holtzman, 1994; Nehlig et al, 1994). Thus, caffeine's actions in the brain are likely due to both adenosine receptor antagonism as well as amplification of dopamine neurotransmission.

The adolescent period is characterized by the maturation of brain systems including higher-order processing areas and a series of changes within the mesocorticolimbic dopamine system (Gladwin et al, 2011). It is known that adolescents respond differently to caffeine compared with adults. For example, adolescent rats are more sensitive to caffeine given they exhibit higher locomotor activation to caffeine compared with adults (Marin et al, 2011). Chronic caffeine consumption produces tolerance to caffeine to a greater extent in adolescents compared with adults, suggesting that adolescent animals may exhibit greater brain changes associated with chronic caffeine consumption 
(Rhoads et al, 2011). Chronic caffeine exposure in adolescents also produces behavioral cross-sensitization with methylphenidate when tested in adulthood in the absence of caffeine (Boeck et al, 2009). Given the differences in sensitivity and susceptibility adolescents display to the behavioral changes produced by chronic caffeine exposure, we hypothesized that caffeine consumption during adolescence may enhance the behavioral sensitivity to cocaine by producing changes in protein expression and dopamine release within the NAc.

\section{MATERIALS AND METHODS}

\section{Animals}

Male Sprague-Dawley rats (Charles River) were received on either postnatal day 21 (P21) or P60 and double housed with food and water ad libitum. All experimental procedures were conducted during the light period of a 12-h light/dark cycle and were completed in accordance with the guidelines established by the Institutional Animal Care and Use Committee at the University of Colorado Boulder.

\section{Drugs}

The nonselective adenosine receptor antagonist, caffeine, was purchased from Fisher Scientific (Waltham, MA). The dopamine $\mathrm{D}_{2}$ receptor agonist, quinpirole $((-)$-quinpirole hydrochloride), and cocaine hydrochloride were obtained from Sigma-Aldrich (St Louis, MO). All drugs, except caffeine, were dissolved in sterile-filtered physiological saline. Caffeine was dissolved in tap water.

\section{Caffeine Consumption Procedure}

Seven days after arrival, caffeine-consuming rats were given access to a single bottle containing caffeine in water $(0.3 \mathrm{~g} / \mathrm{l})$ for 28 days (adolescent: P28-P55 or adult: P67-95; Figure 1). Age-matched control groups continued to receive water throughout the procedure. Caffeine and water consumption were monitored throughout the procedure. Following 28 days of caffeine exposure, the caffeine solution was replaced with water for the remainder of the experiment and behavioral testing was initiated at least 7 days after the last caffeine exposure. Thus, all behavioral testing and tissue collection were performed in the absence of caffeine between P62 and P82 or P101 and 121, periods corresponding to adulthood (Spear, 2000). Behavioral measures, tissue collection, and microdialysis studies were performed in separate cohorts of animals.

\section{Locomotor Activity}

Locomotor activity was conducted according to previously published procedures (Merritt and Bachtell, 2013). Briefly, animals underwent habituation to the locomotor chambers for $2 \mathrm{~h}$ on P62-65 (adolescent studies) or P101-104 (adult studies). On the following day, they were tested for cocaine- or quinpirole-induced locomotion in a single $4 \mathrm{~h}$ within-session escalating dose paradigm, where increasing doses of cocaine (vehicle, $2.5,7.5$ and $15 \mathrm{mg} / \mathrm{kg}$, i.p.) or the dopamine $\mathrm{D}_{2}$ receptor agonist, quinpirole, (vehicle, 0.1, 0.3 and $1.0 \mathrm{mg} / \mathrm{kg}$, i.p.) were administered hourly. Locomotor activity was measured as the number of beam breaks during each hour of the testing period.

\section{Place Conditioning}

Place conditioning began 7 days following caffeine consumption (P62 for adolescent studies and P101 for adult studies) as described in the Supplementary Methods. Briefly, a three-phase procedure was conducted as follows: day 1-20 min pre-conditioning session, days $2-4-$ six $30 \mathrm{~min}$ conditioning sessions (0300 hours saline; 1500 hours cocaine) and day 5-20 min post-conditioning session. During the pre- and post-conditioning session, time spent in each compartment was recorded and the animals' preference was determined by subtracting the time in the drugpaired compartment from the time in the saline-paired compartment. We used 7.5 and $15 \mathrm{mg} / \mathrm{kg}$ cocaine to condition a place preference. The $7.5 \mathrm{mg} / \mathrm{kg}$ cocaine was chosen because our previous studies have demonstrated that it does not reliably produce a place preference in all rats (Merritt and Bachtell, 2013), making this cocaine dose useful in identifying differences in the development of a place preference between water- and caffeine-consuming groups.

\section{Sucrose Preference}

A two-bottle choice paradigm was used to test sucrose preferences. Seven days after caffeine removal (P62), rats were habituated to drink water from two bottles for 3 days. The experimental procedures were conducted over the subsequent 4 days where consumption was measured between 1800 and 2200 hours, a period corresponding to the onset of the dark cycle. On each day, the bottles were replaced during this period as follows: day 1-water/water, day 2 -water $/ 0.5 \%$ sucrose, day 3-water/water, and day 4 -water $/ 0.05 \%$ sucrose. Total consumption and a preference ratio ((sucrose consumption/total consumption $) \times 100$ ) were used for analysis.

\section{Dopamine Microdialysis}

On P62 (7 days following caffeine exposure), unilateral microdialysis cannula (CMA Microdialysis, Solna, Sweden) were implanted under halothane anesthesia (1-2.5\%) into either the right or left NAc shell (relative to bregma: $\mathrm{AP}=+1.7, \mathrm{ML}= \pm 0.8, \mathrm{DV}=-6.0$ ) in a counterbalanced manner. Testing began $\sim 1$ week after recovery from surgical procedures $(\sim \mathrm{P} 69)$. The evening before microdialysis testing, animals were transferred to the testing room and placed into separate plexiglass bowls containing bedding and ad libitum food and water. Microdialysis probes were inserted through the guide cannula and artificial CSF $(145 \mathrm{mM} \mathrm{NaCl}, 2.7 \mathrm{mM} \mathrm{KCl}, 1.2 \mathrm{mM} \mathrm{CaCl}$, and $1.0 \mathrm{mM} \mathrm{KCl}$ ) was perfused through the probes overnight using a BASi infusion pumps at a flow rate of $0.2 \mu \mathrm{l} /$ $\mathrm{min}$ overnight. The flow rate was increased to $1.5 \mu \mathrm{l} / \mathrm{min}$ the next morning. Following $90 \mathrm{~min}$ of equilibration, three 20 min baseline samples were collected for the first hour of the experiment. Before the fourth sample tube was inserted, rats received cocaine $(5 \mathrm{mg} / \mathrm{kg}$, i.p.). This dose produces a submaximal increase in extracellular dopamine in the NAc 
a

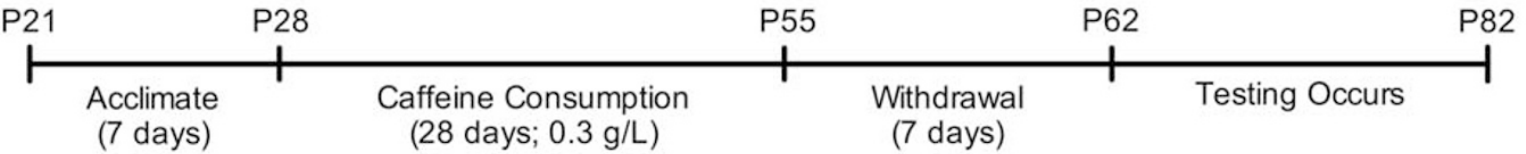

b
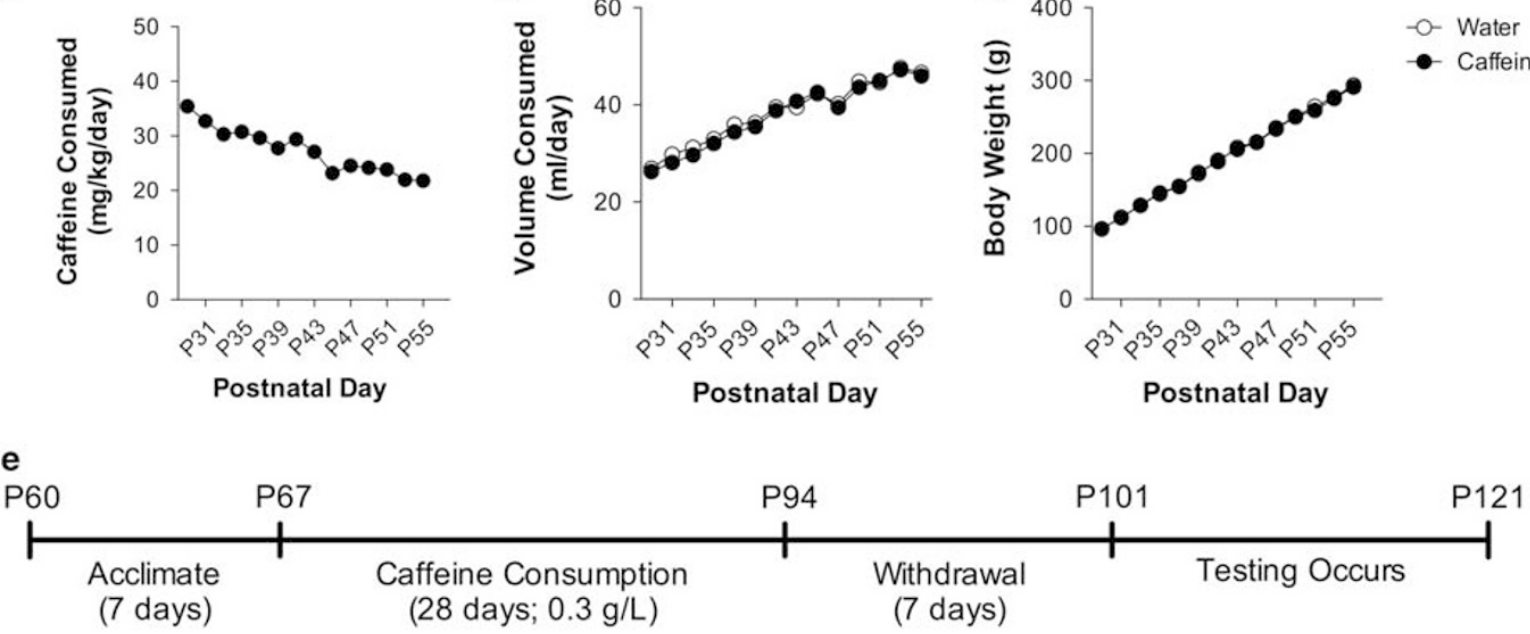

f

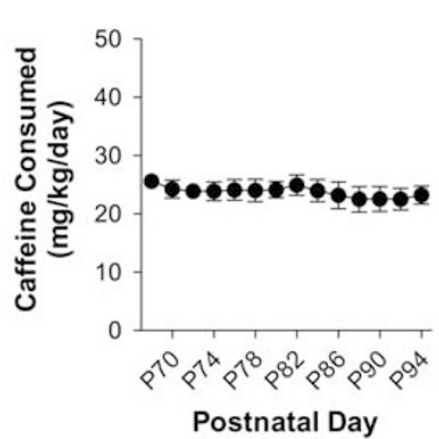

C

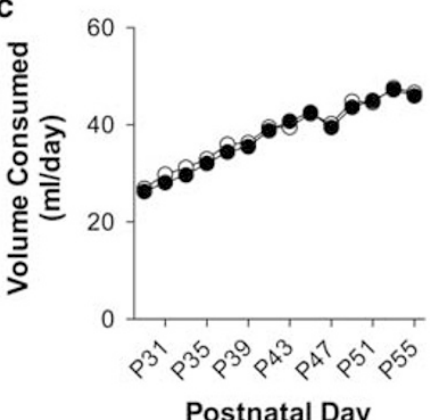

d

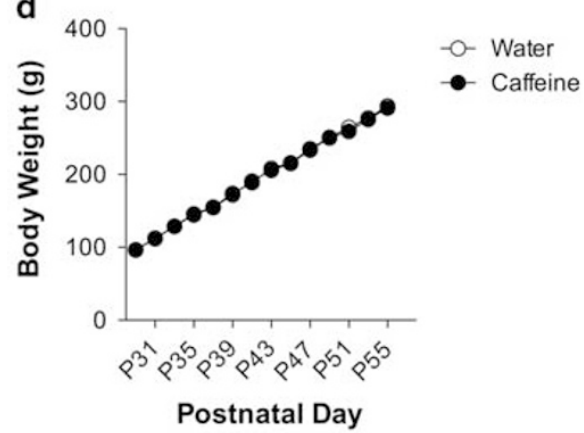

Postnatal Day
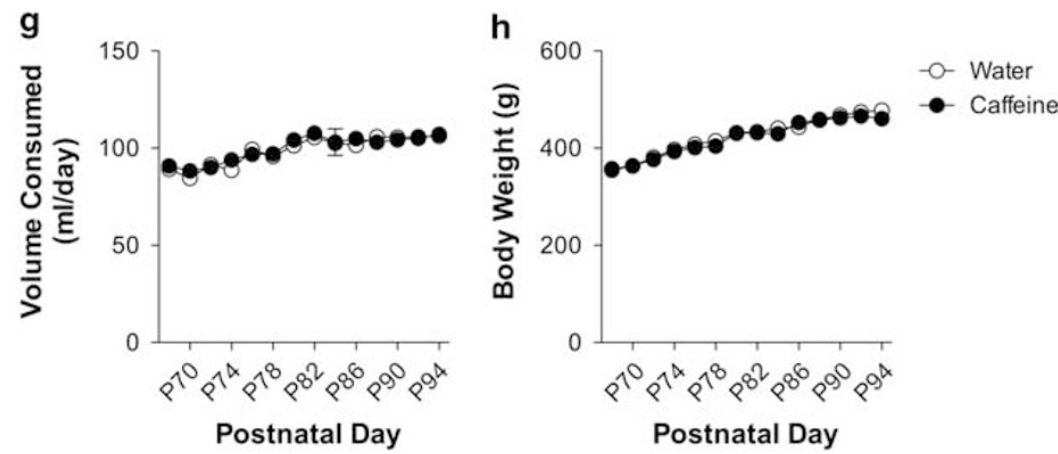

Figure I Caffeine consumption paradigm. (a) Time line of the model of adolescent caffeine consumption. Adolescent rats (P28-P55) consumed caffeine $(0.3 \mathrm{~g} / \mathrm{I})$ and were tested in the absence of caffeine during adulthood (P62-P82). (b) Adolescent rats consumed an average of $27.34 \pm 1.128 \mathrm{mg} / \mathrm{kg} / \mathrm{day}$, although the dose diminished over the adolescent period $\left(F_{14,225}=130.2, p<0.000 \mid\right.$ ). (c) There were no differences in the volume of fluid consumed by the caffeine-consuming rats $(n=16)$ compared with the water controls $(n=16)$. (d) Adolescent rats from both groups gained weight equivalently over the course of the consumption procedures. (e) Time line of the model of adult caffeine exposure. Adult rats (P67-P95) consumed caffeine (0.3 g/l) and were tested in the absence of caffeine (PIOI-PI 2 I). (f) The caffeine consumed remained stable over the procedure resulting in an average $23.78 \pm 0.24 \mathrm{mg} / \mathrm{kg}$ of caffeine consumed per day. (g) There are no differences in the volume of fluid consumed by the caffeine-consuming rats $(n=10)$ compared with the water controls $(n=10)$. (h) There were also no differences in weight gain in the caffeine-consuming rats compared with the water controls.

and enables the detection of enhanced sensitivity for dopamine release. Samples were taken every $20 \mathrm{~min}$ for $3 \mathrm{~h}$ (total of nine samples) after injections, as previous studies indicate that cocaine-induced dopamine increases resolve within this time frame. Dopamine was quantified using an HPLC with electrochemical detection (ESA-Dionex, Sunnyvale, CA) in samples from animals whose cannulae were verified with cresyl violet staining post-mortem to be located within bounds of the desired region. One animal was removed from the study due to inaccurate placement.

\section{Immunoblotting}

Seven days following caffeine consumption (adolescent studies: P62 or adult studies: P101), rats were killed by rapid decapitation and bilateral $1 \mathrm{~mm}^{3}$ tissue punches were taken from chilled tissue slices containing the NAc and the caudate-putamen. Tissue punches were homogenized immediately and stored at $-80{ }^{\circ} \mathrm{C}$ until protein levels were quantified by a Lowry protein assay. Samples $(15 \mu \mathrm{g} /$ well $)$ from each animal were separated by SDS-PAGE and electrophoretically transferred to PVDF membranes. Blots were incubated with affinity-purified primary antibodies (see Supplementary Methods). All blots were stripped and re-probed for the loading control protein, $\beta$-tubulin. Secondary antibodies were detected by enhanced chemiluminescence (ECL film) and densitized. Blots were run with equal numbers of water-exposed control and caffeine-exposed samples per gel and loaded in an alternating manner. The results were quantified using Image J and the optical density for the proteins was normalized to $\beta$-tubulin. 


\section{Data Analysis}

The effects of caffeine consumption on the various behavioral and neurobiological outcomes were analyzed separately for adolescent and adult consumption studies. Body weight and consumption data $(\mathrm{mg} / \mathrm{kg} /$ day and $\mathrm{ml} /$ day) were analyzed using a two-way mixed-design ANOVA with consumption group (between) and days (within) as factors. Locomotor data were analyzed using a two-way mixed-design ANOVA with consumption group (between) and cocaine or quinpirole dose (within) as factors. Place conditioning data were analyzed using a two-way betweensubject ANOVA with consumption group and cocaine dose as factors. Dopamine measures in the microdialysis experiments were analyzed with either an unpaired $t$-test to test for consumption group differences in basal dopamine or a two-way mixed-design ANOVA for cocaine-induced dopamine release with consumption group (between) and time (within) as factors. Finally, effects of caffeine exposure on protein expression were analyzed separately using an unpaired $t$-test. In all cases, significant interactions and main effects were followed by planned comparisons using one-way ANOVA or Bonferroni's correction.

\section{RESULTS}

\section{Caffeine Consumption During Adolescence}

Throughout the caffeine-drinking procedure (Figure 1), caffeine consumption ( $\mathrm{mg} / \mathrm{kg} /$ day), the volume of fluid consumed per day (ml/day), and body weights $(\mathrm{g})$ were recorded. Figure 1 displays data from one cohort of adolescents $(n=32)$ and adult animals $(n=20)$ used for cocaineinduced locomotor testing. Caffeine consumption averaged $\sim 27.34 \pm 1.13 \mathrm{mg} / \mathrm{kg} /$ day (Figure $1 \mathrm{~b}$ ) and $23.78 \pm 0.24 \mathrm{mg} /$ $\mathrm{kg} /$ day (Figure 1f) for adolescent and adult animals, respectively. No differences between the water and caffeine groups were observed in either volume of fluid consumed (Figure $1 \mathrm{c}$ and g) or body weight (Figure $1 \mathrm{~d}$ and $\mathrm{h}$ ). In adolescent animals, there was a significant increase in total fluid consumption (days: $\mathrm{F}_{13,429}=255.3, p<0.0001$ ) and body weight (days: $F_{13,377}=3421, p<0.0001$ ) during the procedure. Likewise, adult animals also showed a significant increase in total fluid consumption (days: $F_{13,112}=14.11$, $p<0.0001$ ) and body weight (days: $\mathrm{F}_{13,252}=491.8, p<0.0001$ ) across the procedure. Analogous consumption data (data not shown) were collected for each cohort of adolescent and adult rats that were run through this procedure before examining all of the behavioral and neurobiological measures reported below.

\section{Adolescent Caffeine Consumption Increases Cocaine Locomotor and Reward Sensitivity}

To determine whether caffeine exposure during the adolescent period altered sensitivity to cocaine in adulthood, we examined locomotion to escalating doses of cocaine $(0,2.5$, 7.5 and $15 \mathrm{mg} / \mathrm{kg}$, i.p.). Caffeine consumption during adolescence increased locomotion to $15 \mathrm{mg} / \mathrm{kg}$ cocaine in adulthood (Figure $2 \mathrm{a}$; dose $\times$ group: $\mathrm{F}_{3,84}=3.45, p<0.05$ ) . To determine whether this effect was specific for chronic caffeine consumption during the adolescent period or whether caffeine consumption influenced cocaine sensitivity regardless of the developmental period, we performed an analogous experiment in which adult animals consumed caffeine and were tested 7 days after removal of caffeine. Caffeine consumption in adult animals did not influence subsequent cocaine-induced locomotor sensitivity (Figure $2 b$ ).

In a separate cohort of animals, we examined the effect of adolescent caffeine exposure on the rewarding properties of cocaine using a place-conditioning paradigm. The development of a cocaine-induced conditioned place preference (CPP) for $7.5 \mathrm{mg} / \mathrm{kg}$ cocaine was more pronounced in the animals that consumed caffeine during adolescence compared with controls $\left(F_{1,44}=9.62, p<0.01\right)$. Development of cocaine-induced CPP for $15 \mathrm{mg} / \mathrm{kg}$ cocaine was equivalent between groups. Adult caffeine-consuming animals showed no evidence of enhanced sensitivity for cocaine-induced CPP at the dose $(7.5 \mathrm{mg} / \mathrm{kg}$ ) tested (Figure $2 \mathrm{~d}$ ).

\section{Adolescent Caffeine Consumption has no Effect on Sucrose Consumption and Preferences}

We also tested sucrose consumption and preference in animals that consumed caffeine during adolescence to identify if these effects generalized to preferences for nondrug rewards. All animals displayed a preference for the sucrose-containing solution, and there were no group differences indicating that caffeine consumption during adolescence did not influence taste sensitivity or the ability to experience reward more generally (Supplementary Results).

\section{Adolescent Caffeine Consumption Increases Dopamine $\mathrm{D}_{2}$ Receptor Sensitivity}

Evidence suggests that the expression and sensitivity of the dopamine $\mathrm{D}_{2}$ receptor may correspond to enhanced psychostimulant use (Merritt and Bachtell, 2013; Volkow et al, 2006). We investigated whether adolescent caffeine consumption influenced the sensitivity to the dopamine $\mathrm{D}_{2}$ receptor agonist, quinpirole, using an escalating doseresponse procedure. Caffeine-consuming animals displayed significantly higher locomotor activation at $1 \mathrm{mg} / \mathrm{kg}$ quinpirole (Figure 2e; dose $\times$ group: $\mathrm{F}_{3,81}=4.27, p<0.01$ ). Adult caffeine-consuming animals did not show alterations in dopamine $D_{2}$ receptor sensitivity (Figure $2 \mathrm{f}$ ).

\section{Adolescent Caffeine Consumption Alters Extracellular Dopamine Levels in the NAc}

Given the differences in cocaine-induced locomotion, cocaine CPP and dopamine $\mathrm{D}_{2}$ receptor sensitivity observed in animals exposed to caffeine during adolescence, we next examined the effects of adolescent caffeine consumption on both basal dopamine levels and cocaine-induced dopamine release (Figure 3). Analysis of basal dopamine levels measured $60 \mathrm{~min}$ before cocaine administration revealed a significant reduction in animals that consumed caffeine during adolescence compared with controls (Figure 3a; $t_{10}=2.49, p<0.05$ ). Cocaine-induced dopamine release was increased in all animals following the $5 \mathrm{mg} / \mathrm{kg}$ cocaine (time: $\mathrm{F}_{12,61}=15.04$, $p<0.0001)$. This increase was enhanced in animals that consumed caffeine during adolescence (treatment $\times$ time: $\left.\mathrm{F}_{12,61}=2.70, p<0.01\right)$ at $40\left(t_{61}=4.68, p<0.001\right)$ and $60 \mathrm{~min}$ 
a

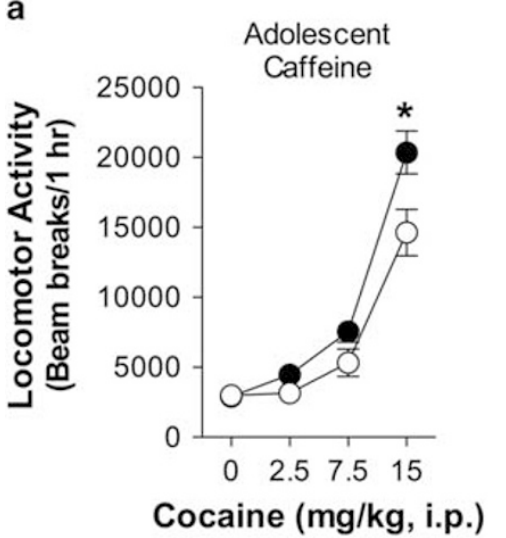

C

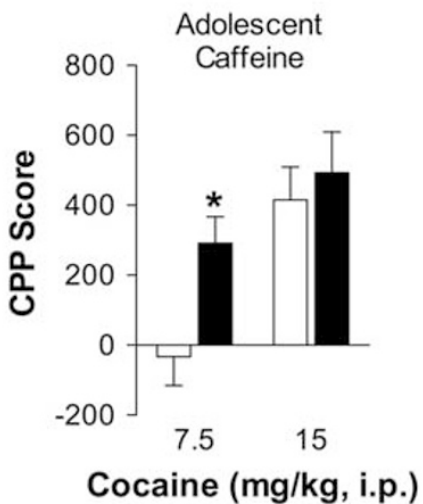

e

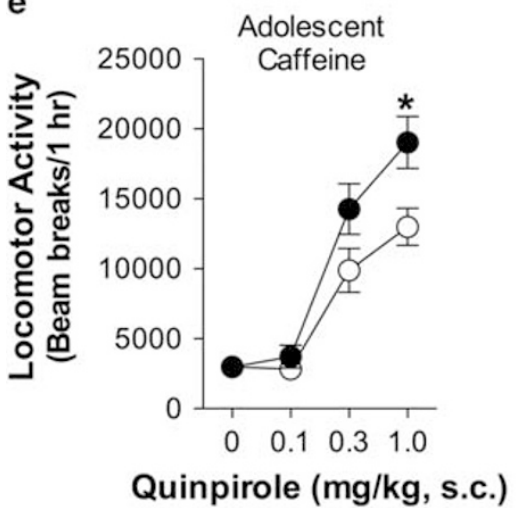

b

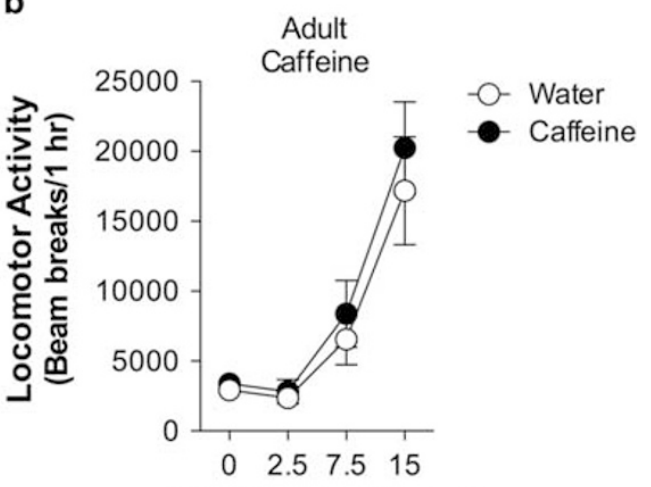

Cocaine (mg/kg, i.p.)

d

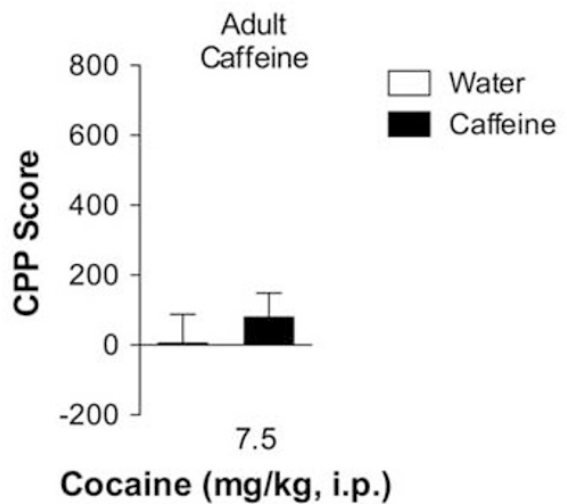

f

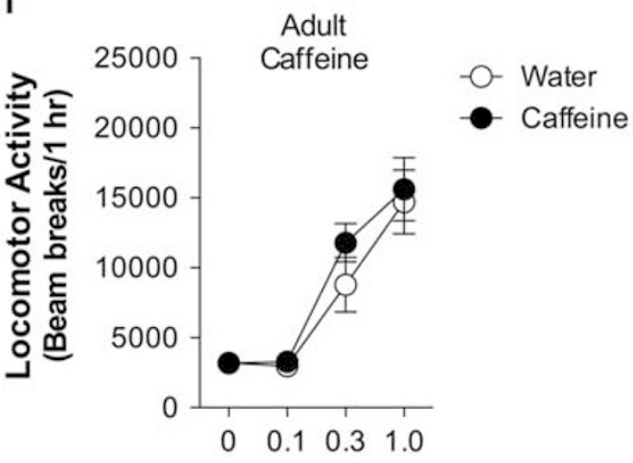

Quinpirole (mg/kg, s.c.)

Figure 2 Caffeine consumption during adolescence enhances behavioral sensitivity to cocaine and quinpirole. (a) Rats were tested on an escalating dose regimen of cocaine $(0,2.5,7.5$ and $15 \mathrm{mg} / \mathrm{kg}$, i.p.). Rats that consumed caffeine during adolescence $(n=16)$ display significantly higher locomotor activity to cocaine $(15 \mathrm{mg} / \mathrm{kg})$ compared with water controls $(n=14)$ following 7 days caffeine withdrawal in adulthood. * Significant from water controls $\left(t_{84}=4.22\right.$, $p<0.00$ l). (b) Adult rats that consumed caffeine $(n=8)$ were not different in their cocaine sensitivity compared with water controls $(n=8)$. (c) Rats that consumed caffeine throughout adolescence $(n=22)$ develop a place preference at a sub-threshold dose of cocaine $(7.5 \mathrm{mg} / \mathrm{kg})$ compared with water controls $(n=25)$ following 7 days caffeine withdrawal in adulthood. * Significant from water controls ( $p<0.05$ Bonferroni's correction). Both groups (water: $n=7$, caffeine: $n=6$ ) developed CPP to $15 \mathrm{mg} / \mathrm{kg}$ cocaine, $\# p<0.05$ Bonferroni's correction. (d) Neither adult rats that consumed caffeine ( $n=17)$ nor water controls $(n=19)$ developed a place preference to $7.5 \mathrm{mg} / \mathrm{kg}$ cocaine. (e) Rats were tested on an escalating dose regimen of quinpirole $(0,0.1,0.3$ and $1.0 \mathrm{mg} / \mathrm{kg}$, s.c.). Rats that consumed caffeine during adolescence $(n=15)$ display significantly higher locomotor activity to $1.0 \mathrm{mg} / \mathrm{kg}$ quinpirole compared with water controls $(n=15)$ following 7 days caffeine withdrawal in adulthood. * Significant from water controls ( $p<0.05$ Bonferroni's correction). (f) Adult rats that consumed caffeine $(n=8)$ were not different in their quinpirole sensitivity compared with water controls $(n=8)$.

$\left(t_{61}=4.24, p<0.01\right)$ following cocaine administration (Figure $3 \mathrm{~b})$. Analysis of the raw dopamine dialysates before and after cocaine administration also revealed a significant difference between the groups $\left(\mathrm{F}_{1,61}=24.54, p<0.001\right)$. Only those rats that confirmed dialysis probe placements in the NAc shell were included in the analysis (Figure $3 c$ ).

\section{Adolescent Caffeine Consumption Alters Protein Expression in the NAc}

We next investigated the effects of chronic caffeine consumption during adolescence on several markers of adenosine and dopamine signaling in the NAc that could 
a

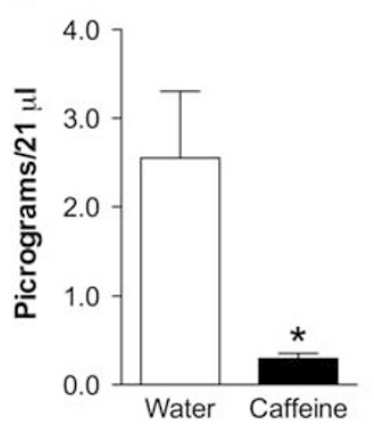

b

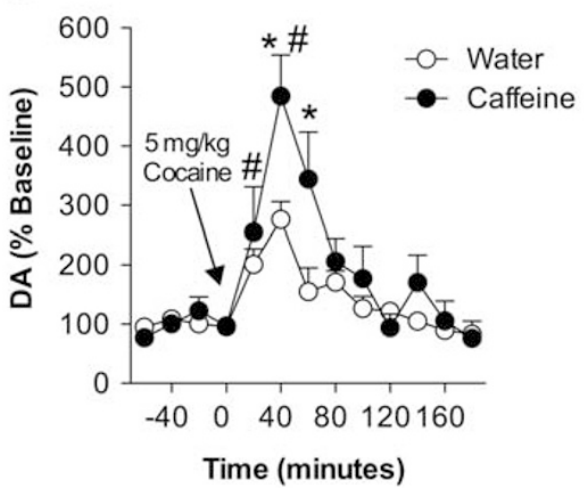

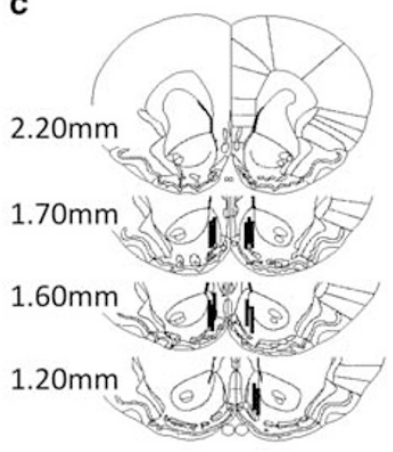

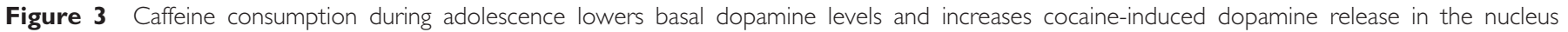

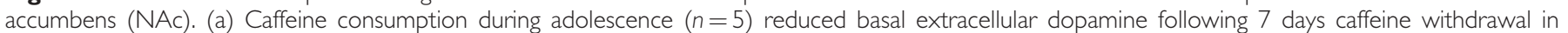

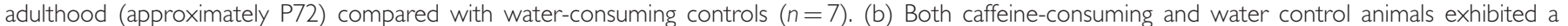

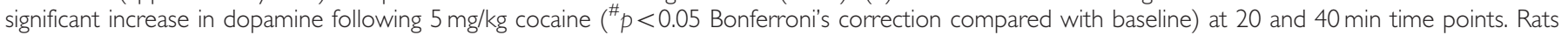

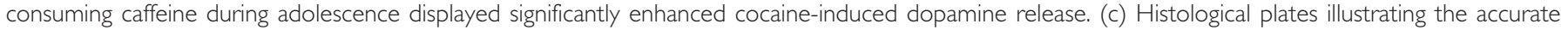
probe placements in the shell region of the NAc. * Significant from water controls ( $p<0.05$ Bonferroni's correction).

contribute to the behavioral and neurochemical effects of caffeine. Protein expression was measured in tissue punches taken from the NAc and $\mathrm{CPu} 7$ days following removal of caffeine (adolescent studies: P62, adult studies: P101). We observed a significant increase in adenosine $A_{1}$ receptor expression (Figure $4 \mathrm{a} ; t_{14}=2.37, p<0.05$ ) and a decrease in adenosine $\mathrm{A}_{2 \mathrm{~A}}$ receptor expression (Figure $4 \mathrm{a} ; t_{14}=4.46$, $p<0.001)$ in the NAc of animals that consumed caffeine during adolescence. Dopamine $\mathrm{D}_{1}$ receptor expression was unaltered in the NAc between caffeine-exposed animals and water controls (Figure $4 \mathrm{~b}$ ), however, dopamine $\mathrm{D}_{2}$ receptors were significantly enhanced in animals that consumed caffeine during adolescence (Figure $4 \mathrm{~b} ; t_{14}=5.82$, $p<0.0001)$. We also assessed the expression of presynaptic markers of dopamine neurotransmission, dopamine transporter (DAT), and tyrosine hydroxylase (TH) in the NAc. Caffeine consumption during adolescence increased DAT expression (Figure $4 \mathrm{c} ; t_{14}=3.37, p<0.01$ ) and did not change $\mathrm{TH}$ expression (data not shown). Finally, we measured total DARPP-32 expression as a marker for NAc medium spiny neurons. DARPP-32 expression was significantly enhanced by adolescent caffeine consumption $\left(t_{14}=3.00, p<0.01\right)$. To identify whether these protein alterations were specific to the NAc, protein expression in the $\mathrm{CPu}$ was also examined. We found no significant differences in the protein expression of animals that consumed caffeine during adolescence in this brain region when compared with water controls (Supplementary Table 1). Similar to adolescent caffeine exposure, caffeine exposure during adulthood produced a significant increase in adenosine $A_{1}$ receptor expression in the NAc $\left(t_{14}=3.97\right.$, $p<0.05$ ), but all other proteins were unchanged (Table 1$)$.

\section{DISCUSSION}

Caffeine increases the rewarding effects of cocaine through its ability to increase dopamine neurotransmission (Bedingfield et al, 1998; Horger et al, 1991; Misra et al, 1986; Solinas et al, 2002). We examined the effects of caffeine consumption during adolescence on cocainemediated behaviors and NAc neurobiology in adulthood following withdrawal from caffeine. Our findings reveal that adolescent caffeine exposure heightens sensitivity to cocaine-induced locomotion and facilitates development of cocaine-induced CPP. Sucrose preference and consumption were not altered by caffeine exposure, suggesting that these changes are specific to drug-related rewards. Adolescent consumption of caffeine also produced alterations in basal and cocaine-induced dopamine release in the NAc. We also observed both enhanced behavioral sensitivity to the dopamine $\mathrm{D}_{2}$ receptor agonist, quinpirole, and enhanced expression of the $\mathrm{D}_{2}$ receptor in the NAc. Finally, we identified increased adenosine $A_{1}$ receptor expression and decreased adenosine $\mathrm{A}_{2 \mathrm{~A}}$ receptor expression in the NAc. Interestingly, adult animals that consumed caffeine for the same length of time did not show the same profile of behavioral or neurobiological alterations, suggesting that the developmental period of adolescence is especially sensitive to caffeine's effects on dopamine signaling in the NAc.

The increase in locomotor sensitivity to cocaine and quinpirole as well as the enhanced development of cocaine CPP may be mediated by the increases in dopamine $D_{2}$ receptor expression observed in the NAc. Previous work has shown that dopamine $\mathrm{D}_{2}$ receptors are necessary for the development of cocaine sensitization (Fontana et al, 1993), and that increased sensitivity of dopamine $D_{2}$ receptors results in the development of cocaine CPP at a subthreshold dose of cocaine (Merritt and Bachtell, 2013). It is unclear whether the increase in dopamine $D_{2}$ receptors reflects changes in presynaptic $\mathrm{D}_{2}$ receptors on dopamine terminals, the postsynaptic $D_{2}$ receptors on medium spiny neurons, or both. Quinpirole administration produces a biphasic locomotor response (Herrera-Marschitz et al, 1988; Vanattou-Saifoudine et al, 2011; Zetterstrom and Fillenz, 1990). Low doses of quinpirole inhibit locomotion by stimulating high-affinity $\mathrm{D}_{2}$ autoreceptors on dopamine terminals, while higher quinpirole doses increase locomotor activity following the saturation of $\mathrm{D}_{2}$ autoreceptors and subsequent stimulation of postsynaptic $\mathrm{D}_{2}$ receptors. We 
a

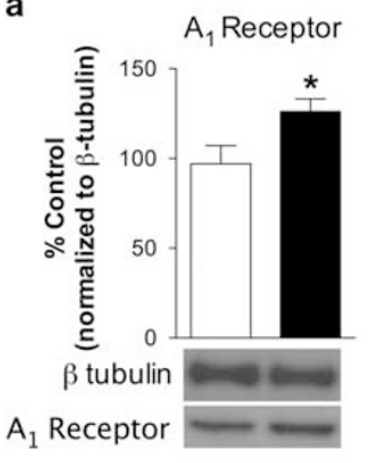

$A_{2 A}$ Receptor

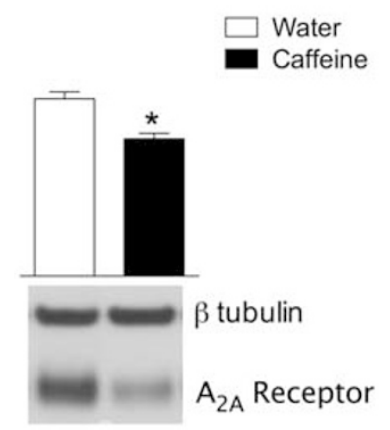

b

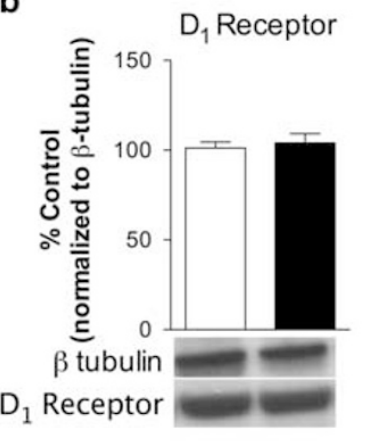

C

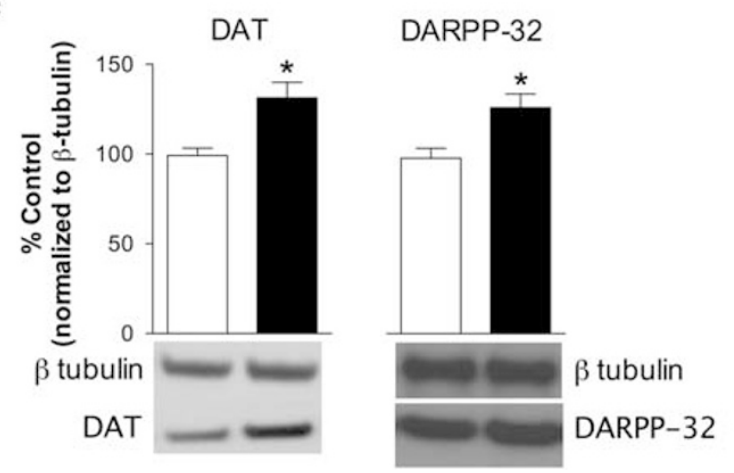

Figure 4 Caffeine consumption during adolescence produces alterations in markers of adenosine and dopamine signaling in the nucleus accumbens (NAc) during adulthood. (a) Adenosine $A_{l}$ receptor expression is increased while adenosine $A_{2 A}$ receptor expression is decreased in the NAc following adolescent consumption of caffeine. (b) Dopamine $D_{\text {। }}$ receptor expression is not altered by adolescent caffeine consumption, but dopamine $D_{2}$ receptor expression is significantly increased in the NAc following adolescent caffeine consumption. (c) Both the presynaptic marker of dopamine terminals, dopamine transporter (DAT), and postsynaptic marker of medium spiny neurons, DARPP-32, are significantly increased in the NAc following adolescent caffeine consumption compared with controls. *Significant from water control ( $p<0.05 t$-test), $n=8 /$ group.

observed enhanced quinpirole sensitivity at the high, postsynaptic doses, suggesting that the increases in dopamine $\mathrm{D}_{2}$ receptors are postsynaptic. Previous work has suggested that increasing signaling in postsynaptic dopamine $\mathrm{D}_{2}$ receptors enhances cocaine-related behaviors like reinstatement (Bachtell et al, 2005; Self et al, 1996), and that decreases, not increases, in dopamine $\mathrm{D}_{2}$ autoreceptors lead to enhanced cocaine sensitivity (Bello et al, 2011).
Table I Effects of Adult Caffeine Consumption on Protein Expression in the Nucleus Accumbens

\begin{tabular}{lcc}
\hline & Control $(\boldsymbol{n}=\mathbf{8})$ & Caffeine $(\boldsymbol{n}=\mathbf{8})$ \\
\hline Nucleus accumbens & & \\
Adenosine $A_{1}$ & $100.0 \pm 5.0$ & $166.5 \pm 14.3^{\mathrm{a}}$ \\
Adenosine $A_{2}$ & $100.0 \pm 11.8$ & $107.5 \pm 7.4$ \\
Dopamine $D_{1}$ & $100.0 \pm 10.0$ & $116.1 \pm 9.8$ \\
Dopamine $D_{2}$ & $100.0 \pm 12.5$ & $115.3 \pm 8.7$ \\
Dopamine transporter & $100.0 \pm 14.9$ & $113.9 \pm 11.0$ \\
Tyrosine hydroxylase & $100.0 \pm 10.0$ & $97.1 \pm 10.4$ \\
DARPP-32 & $100.0 \pm 6.6$ & $109.0 \pm 8.2$ \\
\hline
\end{tabular}

Values that are reported were normalized to b-tubulin and are expressed as $\%$ of water control.

${ }^{a} t_{14}=3.97, p<0.05$.

The enhanced activity of postsynaptic dopamine $\mathrm{D}_{2}$ receptors coupled with the decreased expression of adenosine $\mathrm{A}_{2 \mathrm{~A}}$ receptors in the NAc likely work in concert to amplify cocaine reward and sensitivity. Pharmacological experiments have shown that blockade of adenosine $\mathrm{A}_{2 \mathrm{~A}}$ receptors in the NAc can increase locomotor sensitivity to cocaine (Filip et al, 2006), as well as cocaine seeking (O'Neill et al, 2014; $\mathrm{Wu}$ et al, 2010). Adenosine $\mathrm{A}_{2 \mathrm{~A}}$ receptors exert tonic inhibitory control over $\mathrm{D}_{2}$ receptor signaling within the striatum where $A_{2 A}$ receptor stimulation decreases DA binding at $\mathrm{D}_{2}$ receptors (Ferre et al, 1991). Caffeine-induced enhancements in dopamine $\mathrm{D}_{2}$ receptor expression coupled with diminished adenosine $\mathrm{A}_{2 \mathrm{~A}}$ receptor expression may disengage adenosine's endogenous antagonism over $\mathrm{D}_{2}$-mediated signaling. The increases in total DARPP-32 expression in the NAc also suggest increased dopamine signaling in the NAc that is associated with heightened sensitivity and reward to cocaine (Fienberg et al, 1998; Zachariou et al, 2002). This finding corroborates with a recent study where adolescent caffeine exposure increased both methylphenidate-induced locomotion and total DARPP-32 expression (Boeck et al, 2009). Together, these findings suggest that chronic caffeine consumption during adolescence enhances dopamine receptor signaling in the NAc.

Enhanced dopamine receptor signaling was also accompanied with alterations in extracellular dopamine concentrations in the NAc. Basal extracellular dopamine was significantly lower in the animals exposed to caffeine during adolescence. This is likely associated with a number of other changes observed in the NAc. For example, increases in DAT may translate into lower basal dopamine release in caffeine-exposed rats (Bello et al, 2011; Brodnik et al, 2013; Donovan et al, 1999). Genetic overexpression of DAT on dopamine neurons in the striatum produces decreased basal dopamine levels, as well as behavioral observations similar to our findings, such as increased cocaine-induced locomotion and increased development of cocaine CPP (Donovan et al, 1999; Salahpour et al, 2008). Furthermore, adenosine $\mathrm{A}_{1}$ receptors are expressed on $\sim 30 \%$ of dopamine terminals and act to inhibit dopamine release (Ebstein and Daly, 1982; Jin et al, 1993; Zetterstrom and Fillenz, 1990). We observed 
an increase in expression of adenosine $A_{1}$ receptors that may provide excessive inhibition on the dopamine terminals. Interestingly, adult caffeine consumption also increased adenosine $A_{1}$ receptor expression in the NAc despite the fact that adult caffeine consumption did not recapitulate many of the behavioral changes observed following adolescent consumption. Additional studies should clarify the role of generalized adenosine $\mathrm{A}_{1}$ receptor upregulation following caffeine consumption.

Although we observed decreases in basal dopamine levels, we found that systemic cocaine administration resulted in augmented dopamine release relative to baseline in animals exposed to caffeine during adolescence. It is not clear what, if any, changes in protein expression contribute to the enhanced dopamine release. Interestingly, we did not observe any change in TH, the enzyme associated with dopamine production, suggesting that there is no compensatory enhancement in the production of dopamine. The cortical areas that provide excitatory drive on the mesolimbic system are not fully developed at the time of the caffeine exposure (Pfeifer et al, 2011). It is possible that caffeine consumption alters the connectivity between the prefrontal cortex and the ventral tegmental area and/or the striatal areas. These alterations could indirectly influence phasic activation of the mesolimbic dopamine system and alter dopamine release. It is clear that this phenomenon should be examined more thoroughly to identify alterations in the ventral tegmental area and/or the cortical control regions to identify caffeine-induced abnormalities that would render an overactive dopamine system on cocaine administration.

Our studies suggest that, with the exception of the adenosine $A_{1}$ receptor upregulation, the behavioral and neurobiological changes observed following adolescent caffeine consumption are not observed in adults that consumed caffeine. These findings are in opposition to other studies where acute treatment with caffeine in adult animals increases the development of cocaine CPP (Bedingfield et al, 1998), augments cocaine-induced locomotor activity (Horger et al, 1991; Misra et al, 1986), and results in amplified activation of the mesolimbic dopamine system (Horger et al, 1991). Likewise, chronic caffeine exposure in adult animals increased locomotor activity to cocaine (Gasior et al, 2000; Schenk et al, 1990) and facilitated acquisition of cocaine self-administration (Carroll and Lac, 1998). Many of these studies use higher doses of caffeine as well as shorter exposure lengths both of which could produce different effects. In addition, and perhaps most importantly, all of these studies examined the animals' sensitivity to cocaine concurrent with caffeine administration. This suggests that, although chronic caffeine may enhance the psychostimulant effects of cocaine during the caffeine exposure, these effects are not long lasting and may 'washout' following withdrawal from caffeine. In contrast, it appears that the effects of chronic caffeine exposure during adolescence are prevalent during withdrawal from caffeine.

Caffeine intake is positively correlated with substance-use disorders (Kendler et al, 2006) and has been shown to increase illicit drug use and other risky behaviors in young adults (Miller, 2008). Despite the increase in caffeine consumption among adolescents, very few studies have examined the behavioral or neurobiological effects of adolescent caffeine consumption. We provide new enlightening data suggesting that enduring alterations in reward pathway signaling are an important consequence of chronic adolescent caffeine consumption. On the basis of these findings, it is clear that more extensive studies are needed to determine caffeine's effects on brain development and possibly the permanent effects of adolescent caffeine exposure.

\section{FUNDING AND DISCLOSURE}

The authors declare no conflict of interest.

\section{ACKNOWLEDGEMENTS}

This work was financially supported by United States Public Health Service grants DA029240 and DA033358.

\section{REFERENCES}

Bachtell RK, Whisler K, Karanian D, Self DW (2005). Effects of intra-nucleus accumbens shell administration of dopamine agonists and antagonists on cocaine-taking and cocaine-seeking behaviors in the rat. Psychopharmacology 183: 41-53.

Bedingfield JB, King DA, Holloway FA (1998). Cocaine and caffeine: conditioned place preference, locomotor activity, and additivity. Pharmacol Biochem Behav 61: 291-296.

Bello EP, Mateo Y, Gelman DM, Noain D, Shin JH, Low MJ et al (2011). Cocaine supersensitivity and enhanced motivation for reward in mice lacking dopamine D2 autoreceptors. Nat Neurosci 14: 1033-1038.

Boeck CR, Marques VB, Valvassori SS, Constantino LC, Rosa DV, Lima FF et al (2009). Early long-term exposure with caffeine induces cross-sensitization to methylphenidate with involvement of DARPP-32 in adulthood of rats. Neurochem Int 55: 318-322.

Borycz J, Pereira MF, Melani A, Rodrigues RJ, Kofalvi A, Panlilio L et al (2007). Differential glutamate-dependent and glutamateindependent adenosine A1 receptor-mediated modulation of dopamine release in different striatal compartments. J Neurochem 101: 355-363.

Brodnik Z, Double M, Jaskiw GE (2013). Presynaptic regulation of extracellular dopamine levels in the medial prefrontal cortex and striatum during tyrosine depletion. Psychopharmacology 227: 363-371.

Carroll ME, Lac ST (1998). Dietary additives and the acquisition of cocaine self-administration in rats. Psychopharmacology 137: 81-89.

De Luca MA, Bassareo V, Bauer A, Di Chiara G (2007). Caffeine and accumbens shell dopamine. J Neurochem 103: 157-163.

Donovan DM, Miner LL, Perry MP, Revay RS, Sharpe LG, Przedborski S et al (1999). Cocaine reward and MPTP toxicity: alteration by regional variant dopamine transporter overexpression. Brain Res Mol Brain Res 73: 37-49.

Ebstein RP, Daly JW (1982). Release of norepinephrine and dopamine from brain vesicular preparations: effects of adenosine analogues. Cell Mol Neurobiol 2: 193-204.

Ferre S, von Euler G, Johansson B, Fredholm BB, Fuxe K (1991). Stimulation of high-affinity adenosine A2 receptors decreases the affinity of dopamine D2 receptors in rat striatal membranes. Proc Natl Acad Sci USA 88: 7238-7241.

Fienberg AA, Hiroi N, Mermelstein PG, Song W, Snyder GL, Nishi A et al (1998). DARPP-32: regulator of the efficacy of dopaminergic neurotransmission. Science 281: 838-842. 
Filip M, Frankowska M, Zaniewska M, Przegalinski E, Muller CE, Agnati L et al (2006). Involvement of adenosine A2A and dopamine receptors in the locomotor and sensitizing effects of cocaine. Brain Res 1077: 67-80.

Fontana D, Post RM, Weiss SR, Pert A (1993). The role of D1 and D2 dopamine receptors in the acquisition and expression of cocaine-induced conditioned increases in locomotor behavior. Behav Pharmacol 4: 375-387.

Frary CD, Johnson RK, Wang MQ (2005). Food sources and intakes of caffeine in the diets of persons in the United States. J Am Diet Assoc 105: 110-113.

Fredholm BB, Battig K, Holmen J, Nehlig A, Zvartau EE (1999). Actions of caffeine in the brain with special reference to factors that contribute to its widespread use. Pharmacol Rev 51: 83-133.

Fuxe K, Ferre S, Genedani S, Franco R, Agnati LF (2007). Adenosine receptor-dopamine receptor interactions in the basal ganglia and their relevance for brain function. Physiol Behav 92: 210-217.

Garrett BE, Holtzman SG (1994). D1 and D2 dopamine receptor antagonists block caffeine-induced stimulation of locomotor activity in rats. Pharmacol Biochem Behav 47: 89-94.

Gasior M, Jaszyna M, Peters J, Goldberg SR (2000). Changes in the ambulatory activity and discriminative stimulus effects of psychostimulant drugs in rats chronically exposed to caffeine: effect of caffeine dose. J Pharmacol Exp Ther 295: 1101-1111.

Gladwin TE, Figner B, Crone EA, Wiers RW (2011). Addiction, adolescence, and the integration of control and motivation. Dev Cogn Neurosci 1: 364-376.

Herrera-Marschitz M, Casas M, Ungerstedt U (1988). Caffeine produces contralateral rotation in rats with unilateral dopamine denervation: comparisons with apomorphine-induced responses. Psychopharmacology 94: 38-45.

Horger BA, Wellman PJ, Morien A, Davies BT, Schenk S (1991). Caffeine exposure sensitizes rats to the reinforcing effects of cocaine. Neuroreport 2: 53-56.

Jin S, Johansson B, Fredholm BB (1993). Effects of adenosine A1 and $\mathrm{A} 2$ receptor activation on electrically evoked dopamine and acetylcholine release from rat striatal slices. J Pharmacol Exp Ther 267: 801-808.

Kendler KS, Myers J, O Gardner C (2006). Caffeine intake, toxicity and dependence and lifetime risk for psychiatric and substance use disorders: an epidemiologic and co-twin control analysis. Psychol Med 36: 1717-1725.

Marin MT, Zancheta R, Paro AH, Possi AP, Cruz FC, Planeta CS (2011). Comparison of caffeine-induced locomotor activity between adolescent and adult rats. Eur J Pharmacol 660: 363-367.

Merritt KE, Bachtell RK (2013). Initial d2 dopamine receptor sensitivity predicts cocaine sensitivity and reward in rats. PLoS One 8: e78258.

Miller KE (2008). Energy drinks, race, and problem behaviors among college students. J Adolesc Health 43: 490-497.

Misra AL, Vadlamani NL, Pontani RB (1986). Effect of caffeine on cocaine locomotor stimulant activity in rats. Pharmacol Biochem Behav 24: 761-764.
Nehlig A, Daval JL, Boyet S (1994). Effects of selective adenosine $\mathrm{A} 1$ and $\mathrm{A} 2$ receptor agonists and antagonists on local rates of energy metabolism in the rat brain. Eur J Pharmacol 258: 57-66.

O’Neill CE, Hobson BD, Levis SC, Bachtell RK (2014). Persistent reduction of cocaine seeking by pharmacological manipulation of adenosine $\mathrm{A}$ and $\mathrm{A}$ receptors during extinction training in rats. Psychopharmacology 231: 3179-3188.

Pfeifer JH, Masten CL, Moore WE 3rd, Oswald TM, Mazziotta JC, Iacoboni $\mathrm{M}$ et al (2011). Entering adolescence: resistance to peer influence, risky behavior, and neural changes in emotion reactivity. Neuron 69: 1029-1036.

Rath M (2012). Energy drinks: what is all the hype? The dangers of energy drink consumption. J Am Acad Nurse Pract 24: $70-76$.

Rhoads DE, Huggler AL, Rhoads LJ (2011). Acute and adaptive motor responses to caffeine in adolescent and adult rats. Pharmacol Biochem Behav 99: 81-86.

Salahpour A, Ramsey AJ, Medvedev IO, Kile B, Sotnikova TD, Holmstrand $\mathrm{E}$ et al (2008). Increased amphetamine-induced hyperactivity and reward in mice overexpressing the dopamine transporter. Proc Natl Acad Sci USA 105: 4405-4410.

Schenk S, Horger B, Snow S (1990). Caffeine preexposure sensitizes rats to the motor activating effects of cocaine. Behav Pharmacol 1: $447-451$.

Self DW, Barnhart WJ, Lehman DA, Nestler EJ (1996). Opposite modulation of cocaine-seeking behavior by D1- and D2-like dopamine receptor agonists. Science 271: 1586-1589.

Solinas M, Ferre S, You ZB, Karcz-Kubicha M, Popoli P, Goldberg SR (2002). Caffeine induces dopamine and glutamate release in the shell of the nucleus accumbens. J Neurosci 22: 6321-6324.

Spear LP (2000). The adolescent brain and age-related behavioral manifestations. Neurosci Biobehav Rev 24: 417-463.

Temple JL (2009). Caffeine use in children: what we know, what we have left to learn, and why we should worry. Neurosci Biobehav Rev 33: 793-806.

Vanattou-Saifoudine N, Gossen A, Harkin A (2011). A role for adenosine $\mathrm{A}(1)$ receptor blockade in the ability of caffeine to promote MDMA 'Ecstasy'-induced striatal dopamine release. Eur J Pharmacol 650: 220-228.

Volkow ND, Wang GJ, Telang F, Fowler JS, Logan J, Childress AR et al (2006). Cocaine cues and dopamine in dorsal striatum: mechanism of craving in cocaine addiction. J Neurosci 26: 6583-6588.

Wu J, Lee MR, Choi S, Kim T, Choi DS (2010). ENT1 regulates ethanol-sensitive EAAT2 expression and function in astrocytes. Alcohol Clin Exp Res 34: 1110-1117.

Zachariou V, Benoit-Marand M, Allen PB, Ingrassia P, Fienberg AA, Gonon $\mathrm{F}$ et al (2002). Reduction of cocaine place preference in mice lacking the protein phosphatase 1 inhibitors DARPP 32 or Inhibitor 1. Biol Psychiatry 51: 612-620.

Zetterstrom T, Fillenz M (1990). Adenosine agonists can both inhibit and enhance in vivo striatal dopamine release. Eur $J$ Pharmacol 180: 137-143.

Supplementary Information accompanies the paper on the Neuropsychopharmacology website (http://www.nature.com/npp) 